\section{DEATH FROM TUBERCULOSIS}

BY

\section{W. M. MACLEOD, M.B.E., M.B., M.R.C.P.} Consultant Chest Physician, Southampton

From the Central Chest Clinic, Southampton

"Tuberculosis Undefeated" is the succinct title used by Professor Crofton for his Marc Daniels Memorial Lecture (Crofton, 1960). Nowhere is this fact more clearly established than in the Registrar-General's report for 1959, which shows the 2,620 men and 854 women died from this disease during the year.

That tuberculosis could be eliminated from Great Britain with available resources may be inferred from Crofton's review and the reports of other workers, such as Thomas et al. (1960) in Birmingham. However, with our present inadequate preventive measures we have to accept continuing infection and so face the three remaining failures of the tuberculosis services. Firstly, late diagnosis of advanced and infectious disease with consequent severe lung damage. Secondly, relapse during or after treatment, often associated with an organism resistant to the standard drugs. Finally, there is death from tuberculosis; sometimes a tragic prelude to its recognition, but more usually following some years after diagnosis.

Southampton is a port town and a county borough with a population growing from 177,100 in 1953 to over 200,000 by 1950 . During the past 10 years the death rate from tuberculosis has fallen from 35.4 in 1950 to 14.4 per 100,000 , but remains higher than the general trend for England and Wales (Fig. 1).

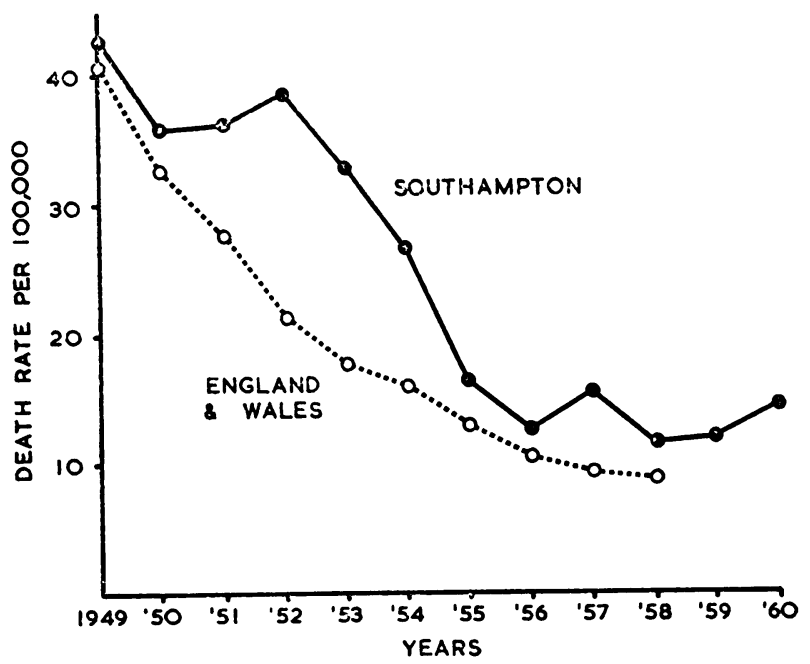

FIG. 1.-Death rate per 100,000 population in Southampton compared with England and Wales, 1949-60.

Having reviewed the pattern of recognized tuberculosis in the borough (Macleod, 1960), we have studied in some detail the progress of those who eventually died from the disease during the eight years 1953 to 1960 . Over this period there were 297 deaths (235 men and 62 women). In the elderly it is often difficult to separate the features of tuberculosis from those relating to ageing and other diseases of old age. We decided, therefore, to limit our study to those dying under the age of 66 years. There were 210 persons in this age group. In 13 the records were inadequate for study, leaving 157 men and 40 women.
Among the 197 persons reviewed 18 had died before their infection was recognized, and 13 other cases were notified posthumously. Others had suffered for many years and their deaths are the final curtain of the prechemotherapy era. But 59 persons-nearly 30\%-had been diagnosed since 1952 as cases of tuberculosis and died in spite of all available modern therapy. The time elapsing between recognition of tuberculosis and death is shown in the Table.

Interval Between Diagnosis and Death from Respiratory Tuberculosis for Males and Females Dying During 1953 to 1960 Inclusive

\begin{tabular}{|c|c|c|c|}
\hline Interval & & Males & Females \\
\hline $\begin{array}{l}\text { None } \\
\text { Within } 1 \text { year } \\
\text {," } 2 \text { years } \\
\text {," } 3 \text {, } \\
\text { ", 5-10", } \\
10 \text { years and over }\end{array}$ & $\begin{array}{ll}\ldots & . \\
\cdots & \cdots \\
\cdots & \cdots \\
\cdots & \cdots \\
\cdots & \cdots \\
\cdots & \cdots\end{array}$ & $\begin{array}{r}26 \\
10 \\
13 \\
15 \\
6 \\
54 \\
33\end{array}$ & $\begin{array}{r}5 \\
2 \\
1 \\
4 \\
2 \\
15 \\
11\end{array}$ \\
\hline
\end{tabular}

In trying to assess the factors responsible for failure it is pertinent to consider first the terminal form of death and later to relate this to the disease at the time of notification (Fig. 2).

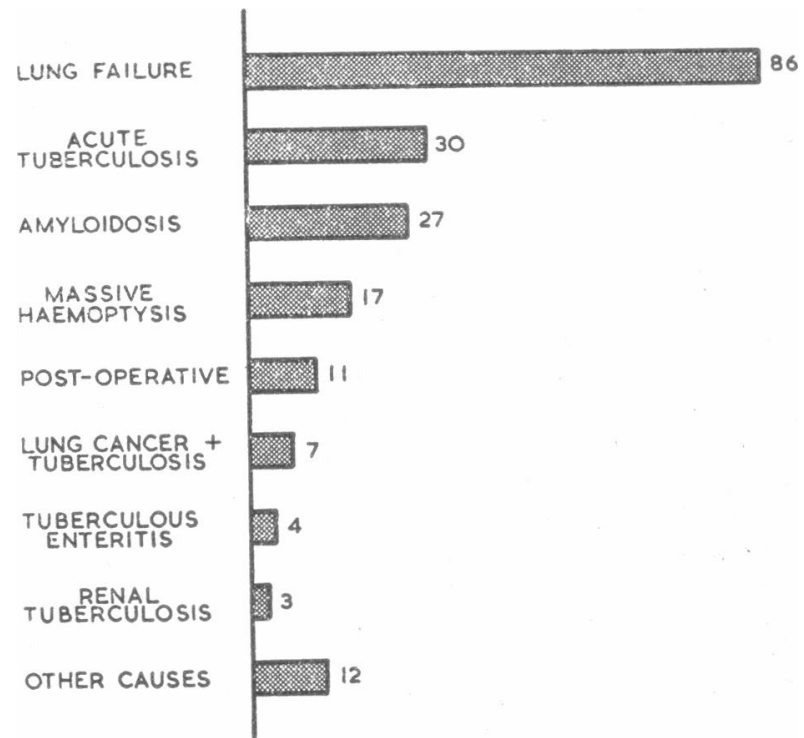

Fig. 2.-Main causes of death from tuberculosis in Southampton, 1949-60.

\section{The Disease at Death \\ Lung Failure}

In 86 persons the terminal phase, often lasting some months, was one of progressive deterioration of respiratory reserve. Extensive tuberculous disease had led to irreparable lung damage, so that a simple infection such as influenza or bronchitis was sufficient to weight the balance in favour of death. In such persons there may be no residual cavitation and sputum conversion may have been present for years, but death has been attributed correctly to tuberculosis. Others with gross lung disease died from terminal tuberculous bronchopneumonia. Late diagnosis with advanced and infectious disease is still too common, and it would seem that we must expect this tragic end-result, even with full modern chemotherapy, for some years to come.

Emphysema with accompanying chronic bronchitis added its embarrassment to 36 persons, but the tuberculous damage remained the dominant causal factor for such deaths. 


\section{Amyloid Disease}

Renal failure from secondary amyloidosis killed 27 people. Amyloidosis was also present at death in another eight. All died with extensive lung disease and most had had a positive sputum throughout their illness. In four there was a tuberculous empyema, an endowment of a bad pneumothorax. However, two patients had negative sputum tests for some years and in several others there was no gross infection with secondary organisms, the disease being similar to that found in many who had not succumbed with this complication. It would seem that while amyloidosis is more likely to occur with persisting cavitation, secondary infection, and empyema, these factors alone are not an adequate explanation of its development.

The recognition of this complication may be important, for during the eight years under review three other persons recovered from their tuberculosis with apparent reabsorption of the amyloid deposit following pleuropneumonectomy.

\section{Acute Tuberculosis}

Acute miliary tuberculosis with the characteristic mottling on the radiograph, continuing fever, and maybe meningitis can hardly be overlooked. But there are other phases of acute disseminated tuberculosis that are missed until late in the progress of the disease or first recognized only at necropsy. Such unfortunate patients may present as problems of unexplained continuing fever without any localizing signs of disease. It is forgotten that miliary dissemination, even in the lungs, can accompany a normal chest radiograph.

Acute disseminated tuberculosis in others may masquerade as a "blood disease," featuring a study for the haematologist, showing pancytopenia or simulating acute leukaemia or myelosclerosis (Medd and Hayhoe, 1955).

In women, unsuspected pelvic tuberculosis may erupt with fever, resistant anaemia, and critical ill-health, while the cause of the infection remains unrecognized until near death.

Each year there are a number of elderly men with chronic bronchitis and many years' history of cough with purulent sputum who die, not from their bronchitis alone or related pneumonitis, but from acute tuberculous bronchopneumonia.

The treachery of these presentations is underlined by the frequency of their occurrence, not in the garret or the back-street bedroom, but in the middle of wards in hospitals equipped with every modern diagnostic facility at hand except a daily alert for the tubercle bacillus (Treip and Meyers, 1959). We are becoming so accustomed to the ready diagnosis of tuberculosis through miniature radiography that a satisfactory chest $x$-ray report is accepted as denying the presence of tuberculous infection, and so the agent behind these acute and serious illnesses remains unrecognized.

In all such obscure disease with relentless downward progress, where investigations have failed to show the cause, awareness of acute tuberculosis and the therapeutic test of streptomycin and its allies may avert disaster.

In this study there were 30 persons who died from acute tuberculosis; 20 of these had bronchopneumonia and 10 had haematogenous dissemination.

\section{Tuberculous Enteritis}

It is possible that some persons with tuberculous ulceration of the small bowel show no symptoms of intestinal disease. The ulceration, unsuspected, heals under routine tuberculous chemotherapy, leaving little or no scarring.

When tuberculous enteritis presents with symptoms of small-bowel disorder it is always associated with active pulmonary disease and proves to be the most serious complication of this infection. The ulceration healing with fibrosis, death follows from small-bowel obstruction and multiple strictures, from perforation, or from malabsorption and consequent inanition.

During the first six-year period covered by this review five patients had this complication. Four of these died as a direct consequence of their enteritis. The sole survivor required a laparotomy early in her illness and three short-circuits, and two years later she developed malnutrition with steatorrhoea. This patient improved with appropriate diet and tetracycline, but had a further episode of subacute bowel obstruction not requiring operation. She is now well five years after the start of her treatment. During 1958 another two patients were admitted to hospital with this dreaded complication. In both prednisone was given from the start of their treatment together with streptomycin, isoniazid, and sodium para-aminosalicylate. After a smooth and uneventful convalescence they both appear to have made a complete recovery.

This small experience suggests that steroid therapy should be combined with routine antituberculous drugs in all those known to have bowel ulceration.

\section{Other Terminal Causes of Death}

Seventeen patients, all with advanced disease, died from a massive haemoptysis. There were three deaths from renal tuberculosis. In seven patients their disease was associated with lung cancer. There were 11 postoperative deaths.

Advanced tuberculosis was robbed of its victims in 12 others who died from various causes such as cerebral haemorrhage, ischaemic heart disease, etc.

\section{The Disease at Notification}

The severity of the disease at the time of diagnosis in those who eventually died from it is illustrated in Fig. 3. This has been recorded, using the six standard radiographic zones. Where an $x$-ray picture was not available, as in cases found at necropsy, an assessment has been made. In 13 patients the lungs were apparently free from disease, the illness starting with pleural effusion, spinal Pott's disease, or renal tuberculosis. There were 101 patients in whom more than four zones were already involved at the time of notification. It might have been expected that advanced disease would carry a worse prognosis than early or minimal infection.

Death from tuberculosis is first and foremost a problem of very late diagnosis. The factors leading to such delay are often intangible. Fear of consumption, with its continuing social and economic penalties, is dominant. There are still many who ignore the appeals of the mass radiography service. The touch-point of the conscience of this resistant core is elusive. 
Other factors are more readily recognized. They are discussed later, for they persist and play their part in deterioration after diagnosis, and so lead to death.

In a few persons the disease is acute in onset and galloping in progression. With such unpredictable behaviour it is unavoidable that diagnosis is not made until the disease is in an advanced stage.

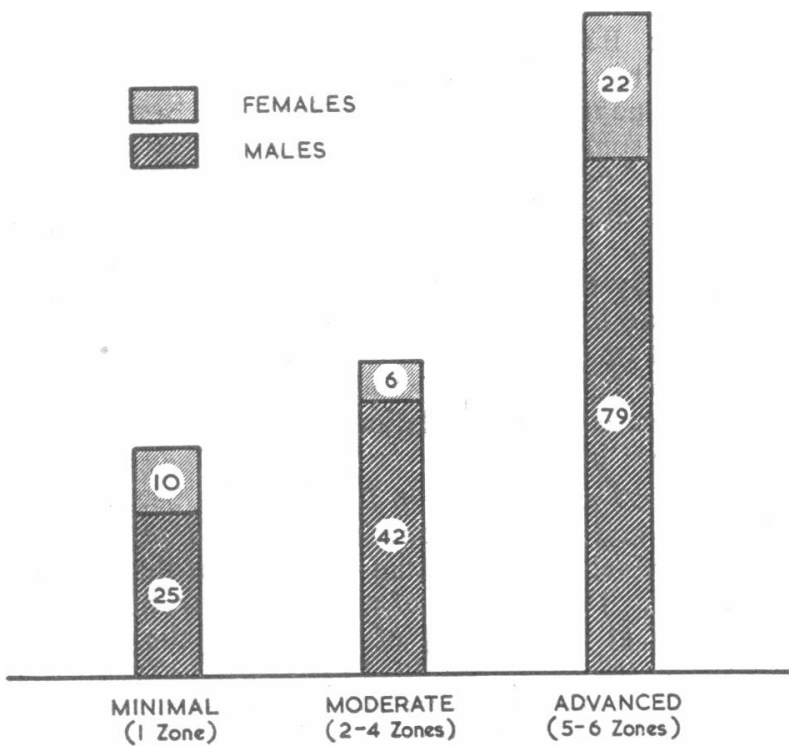

Fig. 3.-Radiological extent of lung disease at notification.

\section{The Interlude Between Diagnosis and Death}

The length of survival in relation to notification is shown in the Table. Eighteen persons were dead before diagnosis, their disease being found at necropsy. In contrast, 44 persons died from their infection 10 or more years after it was recognized.

Irrespective of the extent of their disease at notification, all had advanced disease at death. The main factor which has led to this progression is inadequate treatment. We assessed this by accepting as a minimal standard six months' combined therapy, using two or more effective drugs. By this criterion, treatment in 109 patients out of a total of 197 was below standard. In 24 of these patients their disease had reached an advanced stage before streptomycin became available; most of the other failures occurred in the earlier years under review, when the importance of combined therapy was not fully appreciated. Another carry-over from the early days of tuberculous chemotherapy presented in 40 persons in whom the tubercle bacilli developed a high degree of drug resistance.

The uncooperative patient is well known in any disease group, but in an infection so trivial in symptoms and so demanding of patience this problem causes great anxiety and still defeats almost inexhaustible tact and persuasion. In the present study 41 such persons were found; 10 of these had severe mental disease, 10 were confirmed alcoholics, and others were so troubled by gastric upset that they revolted against their drugs. In most of these persons, however, there was a basis of fear of the disease and its effect on health, fear of death, and fear of economic penalties on the patient and his family. Some, under a penumbra of ignorance and folklore, had a strong sense of guilt and felt the shame of a family disgrace. So strong were such fears that they refused to recognize their failing health until the terminal stages of advanced disease left no escape.

\section{Death Certification}

The Registrar-General has recorded the deaths of 3,094 persons from respiratory tuberculosis during 1960 , compared with 3,474 in 1959 (Registrar-General, 1961). This means that there are still over 3,000 persons a year dying in this country from a preventable and curable disease. Any satisfaction that we may feel in regard to a fall in the mortality figures must be tempered by our awareness of the fallacies of such registration. In Southampton, among 197 known deaths from tuberculosis there were 18 in which the cause was recognized only at necropsy. We may conjecture how many persons with a terminal phthisis or features of acute tuberculosis have been certified as having died from bronchopneumonia or other non-specific ill-defined entity. It is easier in death from renal failure to register chronic nephritis than to detect the causative amyloidosis and its antecedent tuberculous infection. Clinicians may hesitate about the diagnosis of diffuse pulmonary fibrosis and puzzle over the development of severe emphysema and chronic bronchial disease. The preludes of right-sided cardiac failure are glossed over and grouped as "cor pulmonale." All these fatal illnesses may hide a death from tuberculosis, for such does not require a positive sputum. The returns for 1960 should be read as 3,094 plus $x$, and $x$ with a falling recognized mortality becomes each year all the more significant.

\section{Summary}

This paper reviews the factors which have led to the death of 197 persons in Southampton over the last eight years from a preventable and curable disease, tuberculosis. It is a reminder of knowledge that is apt to be forgotten.

Death from tuberculosis is largely a problem of late diagnosis and its accompanying advanced disease. Treatment can result in sputum conversion with inactive lesions, but severe lung damage is irreparable and is the main factor in premature death.

In a few patients we may hope for success with more acceptable drug regimes and with a constant alertness for haematogenous and acute bronchogenic tuberculosis. An awareness of the urgency for steroid therapy in tuberculous enteritis may be life-saving.

This study has been aided by a generous grant from the Research Funds of the Wessex Regional Hospital Board.

\section{REFERENCES}

Crofton, J. (1960), Brit. med. J., 2, 679.

Macleod, W. M. (1960). Tuberculosis in Southampton. A report to the Wessex Regional Board.

Medd, W. E., and Hayhoe, F. G. J. (1955). Quart. med. J., 24, 351.

Registrar-General (1961). Weekly Return No. 14. H.M.S.O., London.

Thomas, H. E., Forbes, D. E. P., Luntz, G. R. W. N., Ross, H. J T., Morrison Smith, J., and Springett, V. H. (1960). Lancet, $2,1185$.

Treip, C., and Meyers, D. (1959). Ibid., 1, 164.

The Australian Government proposes to expand education facilities in Papua-New Guinea, and to establish a university within five years. The existing Papuan Medical College would eventually be added to the proposed university as a fully fledged faculty of medicine. Since 1959 the college has been training Papuans as assistant government medical officers, medical assistants, and nurses. (Radio Australia News, April 9.) 